\title{
DADOS COMPARATIVOS DE MORBIDADE HOSPITALAR DO MUNICIPIO DE CUBATÃo E DO ESTADO DE SÃO PAULO (BRASIL)
}

\author{
Lys Esther Rocha* \\ Clarice Umbelino de Freitas* \\ Jussara Moraes Nunes Ferreira** \\ Cecília Gentil Faria** \\ Marisa Fussae Utiyama Kumagai**
}

ROCHA, L. E. et al. Dados comparativos de morbidade hospitalar do Município de Cubatão e do Estado de São Paulo (Brasil). Rev. Saúde públ., S. Paulo, 22:118-31, 1988.

RESUMO: Realizou-se estudo com o objetivo de caracterizar a morbidade hospitalar do Município de Cubatão, SP (Brasil), comparando-a com a do Estado de São Paulo a fim de identificar as principais patologias e subsidiar a atuação dos serviços de saúde do Município. A caracterização da morbidade hospitalar baseou-se na análise dos dados coletados no período de julho/1983 a junho/1984. As principais causas de internação do Município de Cubatão nos três estabelecimentos hospitalares foram: Complicações da Gravidez, do Parto e do Puerpério (23,63\%); Doenças do Aparelho Respiratório $(22,8 \%)$; Doenças das Glândulas Endócrinas, da Nutrição e do Metabolismo e Transtornos Imunitários $(10,47 \%)$; Doenças do Aparelho Circulatório (10,26\%); Lesões e Envenenamentos $(7,63 \%)$; Doenças do Aparelho Geniturinário (7,56\%) e Doenças do Aparelho Digestivo $(7,16 \%)$. Comparando-se o perfil da morbidade hospitalar de Cubatão com a do Estado de São Paulo observou-se que as Doenças Respiratórias, Doenças das Glândulas Endócrinas, da Nutrição, do Metabolismo e Transtornos Imunitários (compreendendo basicamente as desidratações) e as Lesōes e Envenenamentos são muito mais frequientes em Cubatão, o que pode estar refletindo as péssimas condiçōes do meio ambiente, do saneamento básico, o baixo nível socioeconômico da população e o caráter altamente industrializado do Município. A baixa incidência das Doenças do Sistema Nervoso, dos Neoplasmas, Doenças do Sistema Osteomuscular e Anomalias Congênitas podem estar relacionadas com a precariedade dos serviços de saúde do Município que levam à procura de atendimento em outro local.

UNITERMOS: Hospitais gerais. Morbidade. Pesquisas sobre serviços de saúde. Fatores socioeconômicos.

\section{INTRODUÇÃO}

O desenvolvimento industrial de diferentes regiōes do Brasil determinou alterações no padrão de morbidade e mortalidade. Estas modificações estão sendo avaliadas de maneira precária, pois existem poucos estudos a respeito das características da morbidade dessas comunidades.

Dadas as características da precária situação de saúde do Município de Cubatão, Estado de São Paulo, que têm íntima relação com o processo de trabalho no pólo industrial lá instalado, foi criado em agosto/1983 um grupo de trabalho multi-institucional e multiprofissional, coordenado pela Secretaria da Saúde, com a finalidade de definir o programa de atuação na região. Do programa constava a realização de um levantamento de morbidade. Neste sentido optou-se pela análise dos Boletins de Morbidade Hospitalar cujos dados já vinham sendo coletados pela Secretaria de Estado da Saúde, desde 1971. Os resultados do presente estudo são uma contribuição para o diagnóstico das condições de saúde da população do Município.

O Município de Cubatão é hoje um dos maiores pólos industriais do País, estando próximo à região metropolitana de São Paulo e ao porto de Santos, o que facilita o transporte dos produtos.

O pólo é composto por 23 indústrias de transformação de diferentes ramos tais como:

* Centro de Vigilância Sanitária da Secretaria de Estado da Saúde - Av. São Luís, 99 - 01046 São Paulo, SP - Brasil.

** Fundação Sistema Estadual de Análise de Dados - Av. Cásper Líbero, 464 - 01033 - São Paulo, SP - Brasil. 
siderúrgico, refinação de petróleo, petroquímico, químico, fertilizantes, cimento, gesso e de papel e papelão. Além disso, é constituído por empresas de construção pesada, montagem e manutenção industrial. A instalação deste pólo industrial não foi acompanhada por planejamento das condições habitacionais, de modo que, em 1984 , cerca de $50 \%$ da população morava em favelas, nas encostas da Serra do Mar, sobre manguezais e nas proximidades das indústrias*. As condiçōes de saneamento também são precárias, pois o Município apesar de ser um dos mais ricos do país, não dispõe de rede de esgoto. A Companhia de Tecnologia de Saneamento Ambiental (CETESB) avalia a questão da poluição ambiental como consequiência da concentração de indústrias de alto potencial poluidor, das características topográficas e climáticas da região e da falta de planejamento com que se deu a implantação do pólo e o assentamento urbano da região**. Concluiu-se então que a instalação do pólo industrial de Cubatão não levou em consideração as implicações da concentração industrial sobre a saúde da população.

Pelo censo do $\mathrm{IBGE}^{2}$, em 1980 , a população do Município de Cubatão era de $\mathbf{7 8 . 6 5 2}$ habitantes. A população estimada para 1983 pela Fundação Sistema Estadual de Análise de Dados (SEADE) ${ }^{* * *}$ foi de 87.789 habitantes. A estrutura da população por idade mostra três características principais: grande percentagem de crianças com menos de 5 anos; grande número de adultos jovens, o que forma um abaulamento na pirâmide populacional e um número reduzido de pessoas idosas.

Segundo o levantamento realizado por Medrado-Faria e col. ${ }^{6}$, a população trabalhadora do setor secundário de Cubatão é formada em sua maioria por empregados ligados a empresas de construção pesada, montagem e manutenção industrial $(45,9 \%)$.

Um estudo de morbidade hospitalar compreende dados sobre as doenças, as pessoas internadas $e$ os hospitais, caracterizando a morbidade do serviço como subsídio na formulação de políticas de saúde.

Os levantamentos de morbidade hospitalar apresentam limitações que devem ser levadas em conta: seletividade (refere-se apenas às doenças que motivam uma internação, geral- mente as mais graves); parcialidade (inclui apenas as pessoas que tiveram acesso ao hospital, não podendo ser consideradas como representativas da morbidade geral da comunidade) e grau de fidedignidade dos registros. Os estudos da morbidade hospitalar, baseada na análise dos boletins de morbidade hospitalar da Secretaria de Estado da Saúde, não nos permite analisar diretamente as inter-relações entre saúde e trabalho em que no seu preenchimento não existe a preocupação de caracterizar as patologias relacionadas com o processo de trabalho (por exemplo: a própria Classificação Internacional de Doenças não identifica os diagnósticos de acidentes como acidentes de trabalho); além disso não há a especificação da ocupação, empresa e setor de trabalho dos trabalhadores internados. Com o objetivo específico de estudar as inter-relações do processo de produção com as condiçōes de saúde dos trabalhadores, foi criado o boletim CAH-105 de morbidade ambulatorial que vem sendo preenchido pelos serviços médicos das empresas e ambulatórios dos sindicatos.

Considerando que a industrialização do $\mathrm{Mu}$ nicípio afeta não só aos trabalhadores no seu local de trabalho como também o ambiente no qual residem com suas famílias, o estudo de morbidade hospitalar, mesmo com suas limitações, permite detectar um perfil de doenças relacionadas com as características industriais de Cubatão.

Apesar de seus limites, o conhecimento da morbidade hospitalar em Cubatão é fundamental para que possam ser estabelecidas ações visando combater os determinantes patogênicos decorrentes do processo de produção industrial, bem como para estruturar os serviços de saúde do Município no sentido de que estejam aparelhados para o diagnóstico e tratamento de saúde daquela população.

O objetivo deste trabalho é caracterizar a morbidade hospitalar do Município de Cubatão, comparando-a com a do Estado, para identificar as principais patologias, bem como para fornecer subsídios a ação dos serviços de saúde daquele Município.

\section{MATERIAL E METODOS}

O levantamento da morbidade hospitalar de Cubatão baseia-se na análise dos dados coletados no boletim CAH-101 (atual CAH106) da Coordenadoria de Assistência Hospi-

* CETESB. Relatório da Comissão de Emergência de Cubatão instalada pelo Governo Franco Montoro na época do incêndio na Vila São José, 1984. Dados inéditos.

* CETESB. Programa de controle da poluição ambiental em Cubatão, 1984. Dados inéditos.

*** Fundação SEADE. Estatísticas do Registro Civil, 1983. Dados inéditos. 
talar da Secretaria de Estado da Saúde de São Paulo, no período de julho/1983 a junho/1984. Esse boletim é preenchido mensalmente pelos hospitais, contendo os seguintes dados a respeito de cada paciente: sexo, idade, procedência, data de entrada, tipo de saída, tempo de permanência no hospital, diagnóstico e fonte de financiamento da internação.

O Município de Cubatão tem três estabelecimentos hospitalares, que fornecem assistência hospitalar geral: Hospital de Clínicas Oswaldo Cruz (com 98 leitos e fins lucrativos); Hospital Ana Costa (com 61 leitos e fins lucrativos) e Fundação Cubatense (com 128 leitos mantidos pela Prefeitura).

O período escolhido para o estudo foi de julho/1983 a junho/1984, pois nesta época foram desenvolvidos estudos sobre os atendimentos realizados nos três Postos Municipais ${ }^{4}$, servindo os resultados para complementarem a caracterização da morbidade registrada pelos serviços de saúde de Cubatão. No período estudado ocorreram 14.846 internações no Município. Considerou-se como unidade amostral o egresso, sendo extraída uma amostra proporcional a estes atendimentos. As especificaçōes da amostragem foram as seguintes:

- erro amostral de 2,5\%;

- coeficiente de confiança na ausência de resposta de $10 \%$, ampliando a amostra para 1.548 atendimentos;

- o tamanho da amostra foi calculado com base no cruzamento das variáveis sexo, idade e diagnóstico da pesquisa do Estado de São Paulo, de 1980;

- as unidades amostrais foram coletadas por meio de amostragem sistemática a fim de garantir a participação de todas as unidades na coleta, com a mesma probabilidade.

Assim após rejeitar 67 internações o tamanho da amostra chegou a 1.481 internações, correspondendo a uma amostra de cerca de $10 \%$ do universo.

A codificação dos diagnósticos foi realizada utilizando-se a lista de categorias de três algarismos da Classificação Internacional de Doenças (CID), Revisão de 1975.

Após a análise das frequiências das patologias apresentadas fez-se um trabalho de reagrupamento em 64 itens dentro das 17 categorias da CID, utilizando-se apenas um diagnóstico.
A variável fonte de financiamento foi codificada de acordo com a seguinte classificação: INAMPS (Instituto Nacional de Assistência Médica e Previdência Social), Outras Previdências, Gratuito, Particular-Meia Pensão, Convênio com Empresa, Cooperativa de Trabalho Médico, Associação de Funcionários, Outros (convênios sem especificação).

A codificação e análise dos dados foi efetuada por técnicos da Fundação SEADE e do Instituto de Saúde da Secretaria de Estado da Saúde. A Fundação SEADE realizou levantamento sobre morbidade hospitalar no Estado de São Paulo em $1980^{1}$, tendo utilizado os mesmos instrumentos de coleta de dados, o que possibilitou a comparação entre os resultados de Cubatão e os do Estado.

\section{RESULTADOS E DISCUSSÃO}

\section{Distribuição da Morbidade por Diagnóstico}

As principais causas de internação nos três hospitais do Município de Cubatão foram: Complicações da Gravidez, do Parto e do Puerpério (23,6\%); Doenças do Aparelho Respiratório $(21,1 \%)$; Doenças das Glândulas Endócrinas, da Nutrição e do Metabolismo e Transtornos Imunitários (10,5\%); Doenças do Aparelho Circulatório (10,3\%); Lesões e Envenenamentos $(7,6 \%)$; Doenças do Aparetho Geniturinário $(7,5 \%)$; Doenças do Aparelho Digestivo $(7,2 \%)$; Doenças Infecciosas e Parasitárias $(2,6 \%)$; e Sintomas, Sinais e Afecções Mal Definidas (2,6\%). Juntas, estas nove causas são responsáveis por $93,9 \%$ das internações (Tabela 1).

Comparando-se o perfil da morbidade hospitalar de Cubatão com o do Estado de São Paulo, em $1980^{1}$, observam-se algumas particularidades do Município: as Doenças do Aparelho Respiratório, as Doenças das Glândulas Endócrinas, da Nutrição e do Metabolismo e Transtornos Imunitários e as Lesões e Envenenamentos são muito mais freqüentes em Cubatão, o que pode estar refletindo as péssimas condições do meio ambiente, do saneamento básico, o baixo nível socioeconômico da população e o caráter altamente industrializado do Município.

Tal como acontece no Estado de São Paulo, as Complicações da Gravidez, do Parto e do Puerpério são a principal causa de internação em Cubatão, com uma freqüência de casos semelhantes a do Estado (respectivamente, 23,6 e $23,9 \%$ ). 
TABELA 1

Distribuição dos diagnósticos pelos 17 capítulos da CID. Cubatão, julho/83 a junho/84.

\begin{tabular}{|c|c|c|c|c|c|}
\hline \multirow[b]{2}{*}{ Grupos de diagnósticos } & \multicolumn{2}{|c|}{ Freqüência } & \multirow[b]{2}{*}{ Grupos de diagnósticos } & \multicolumn{2}{|c|}{ Frequiência } \\
\hline & $\begin{array}{l}\text { Abso- } \\
\text { lutos }\end{array}$ & $\begin{array}{l}\text { Rela- } \\
\text { tivos }\end{array}$ & & $\begin{array}{l}\text { Abso- } \\
\text { lutos }\end{array}$ & $\begin{array}{l}\text { Rela- } \\
\text { tivos }\end{array}$ \\
\hline $\begin{array}{l}\text { I - Doenças Infecciosas e Para- } \\
\text { sitárias }\end{array}$ & 38 & 2,6 & $\begin{array}{l}\text { VIII - Doenças do Aparelho Respi- } \\
\text { ratório }\end{array}$ & 327 & 22,1 \\
\hline $\begin{array}{l}\text { 1. Doenças Infecciosas Intes- } \\
\text { tinais }\end{array}$ & 31 & 2,1 & $\begin{array}{l}\text { 1. Doenças do Trato Respi- } \\
\text { ratório Superior }\end{array}$ & 3 & 0,2 \\
\hline 2. Erisipela & 5 & 0,3 & 2. Pneumonia & 273 & 18,4 \\
\hline 3. Doenças Virais & 2 & 0,1 & $\begin{array}{l}\text { 3. Bronquite Aguda, Crônica } \\
\text { ou S/Espec. e Bronqueo- }\end{array}$ & & \\
\hline II - Neoplasmas & 8 & 0,5 & lite Aguda & 8 & 0,5 \\
\hline 1. Neoplasmas Malignos & 3 & 0,2 & 4. Asma & 28 & 1,9 \\
\hline 2. Neoplasmas Benignos & 2 & 0,1 & 5. Pleuris & 6 & 0,4 \\
\hline 3. Outros Neoplasmas & 3 & 0,2 & $\begin{array}{l}\text { 6. Outras Doenças do Apa- } \\
\text { relho Respiratório }\end{array}$ & 9 & 0,6 \\
\hline III - Doenças das Glând. Endó- & & & $\begin{array}{l}\text { IX - Doenças do Aparelho Diges- } \\
\text { tivo }\end{array}$ & 106 & 7,2 \\
\hline $\begin{array}{l}\text { crinas, Nutrição e do Meta- } \\
\text { bolismo e Transt. Imunitá- }\end{array}$ & & & 1. Doenças do Estômago e & & \\
\hline rios & 155 & 10,5 & Duodeno & 25 & 1,7 \\
\hline 1. Transtornos da Glândula & & & 2. Apendicite & 8 & 0,5 \\
\hline Tireóide & 2 & 0,1 & 3. Hérnia da Cavidade Ab- & & \\
\hline 2. Diabetes Mellitus & 13 & 0,9 & lal & 30 & 2,0 \\
\hline 3. Deficiências Nutricionais & 5 & 0,3 & $\begin{array}{l}\text { 4. Outras Gastroenterites e } \\
\text { Colites Não Infecciosas }\end{array}$ & 11 & 0,7 \\
\hline $\begin{array}{l}\text { 4. Transtornos do Equilíbrio } \\
\text { Hidroeletrolítico e Ácido } \\
\text { Básico }\end{array}$ & 134 & 9,0 & $\begin{array}{l}\text { 5. Doenças Crônicas do Fí- } \\
\text { gado e Cirrose, Abcesso } \\
\text { do Fígado e Sequiela e }\end{array}$ & & \\
\hline 5. Outras Doenças Endócri- & 1 & 0.1 & $\begin{array}{l}\text { do Figado e Sequela e } \\
\text { Outras Doenças do Fígado }\end{array}$ & 8 & 0,5 \\
\hline Dencas do Sanque & 1 & 0,1 & $\begin{array}{l}\text { 6. Colelitíase e Outros Trans- } \\
\text { tornos da Vesícula }\end{array}$ & 10 & 0,7 \\
\hline gãos Hematopoéticos & 8 & 0,5 & 7. Hemorragia Gastrointesti- & $\Delta$ & $0 ?$ \\
\hline 1. Anemias & 8 & 0,5 & $\begin{array}{l}\text { nal } \\
\text { 8. Outras Doenças do Apa. }\end{array}$ & 4 & 0,2 \\
\hline Transtomos Mentais & 8 & 0,5 & relho Digestivo & 10 & 0,7 \\
\hline $\begin{array}{l}\text { 1. Alcoolismo e Abuso de Dro- } \\
\text { gas }\end{array}$ & 6 & 0,4 & $\begin{array}{l}\text { X - Doenças do Aparelho Geni- } \\
\text { turinário }\end{array}$ & 112 & 7,6 \\
\hline 2. Outros Transtornos Men- & & & $\begin{array}{l}\text { 1. Doenças do Aparelho Uri- } \\
\text { nário }\end{array}$ & 39 & 2,6 \\
\hline 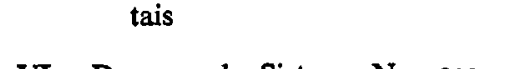 & 2 & 0,1 & $\begin{array}{l}\text { 2. Doenças dos Orgãos Ge- } \\
\text { nitais Masculinos }\end{array}$ & 3 & 02 \\
\hline $\begin{array}{c}\text { VI - Doenças do Sistema Nervoso } \\
\text { e dos Orgãos dos Sentidos }\end{array}$ & 11 & 0,7 & 3. Doenças das Mamas & 3 & 0,2 \\
\hline $\begin{array}{l}\text { 1. Doenças do Sistema Ner- } \\
\text { voso }\end{array}$ & 10 & 0,7 & $\begin{array}{l}\text { 4. Doença Inflamatória dos } \\
\text { Orgãos Pélvicos Femininos }\end{array}$ & 16 & 1,1 \\
\hline 2. Doenças do Olho & 1 & 0,1 & 5. Prolapso Genital & 15 & 1,0 \\
\hline $\begin{array}{l}\text { VII - Doenças do Aparelho Circula- } \\
\text { tório }\end{array}$ & 152 & 10,3 & $\begin{array}{l}\text { 6. Transtornos Não Inflama- } \\
\text { tórios dos Orgãos Pélvi- } \\
\text { cos Femininos }\end{array}$ & 26 & 1,8 \\
\hline $\begin{array}{l}\text { 1. Febre Reumática e Doen- } \\
\text { ça Reumática do Coração }\end{array}$ & 2 & 0,1 & $\begin{array}{l}\text { 7. Transtornos Mentruais e } \\
\text { Outras Hemorragias do }\end{array}$ & & \\
\hline 2. Doença Hipertensiva & 54 & 3,6 & Trato Genital & 10 & 0,7 \\
\hline $\begin{array}{l}\text { 3. Doença Isquêmica do Co- } \\
\text { ração }\end{array}$ & 12 & 0,8 & $\begin{array}{l}\text { XI - Complicações da Gravidez, } \\
\text { do Parto e Puerpério }\end{array}$ & 350 & 23,6 \\
\hline 4. Doenças da Circulação Pul- & & & 1. Aborto & 34 & 2,3 \\
\hline $\begin{array}{l}\text { monar e Outras Formas } \\
\text { de Doenças do Coração }\end{array}$ & 45 & 3,0 & 2. Parto Normal & 141 & 9,5 \\
\hline 5. Doença Cerebrovascular & 16 & 1,1 & $\begin{array}{l}\text { 3. Hemorragia na Gravidez e } \\
\text { no Parto }\end{array}$ & 23 & 1,6 \\
\hline $\begin{array}{l}\text { 6. Doenças das Artérias, Arte- } \\
\text { ríolas e Capilares }\end{array}$ & 3 & 0,2 & 4. Toxemia Gravídica & 7 & 0,5 \\
\hline $\begin{array}{l}\text { 7. Doenças das Veias (Fle- } \\
\text { bites, Varizes, Hemorrói- } \\
\text { das) }\end{array}$ & 20 & 1,3 & $\begin{array}{l}\text { turo ou Falso } \\
\text { rio }\end{array}$ & $\begin{array}{r}21 \\
4\end{array}$ & $\begin{array}{l}1,4 \\
0,3\end{array}$ \\
\hline
\end{tabular}




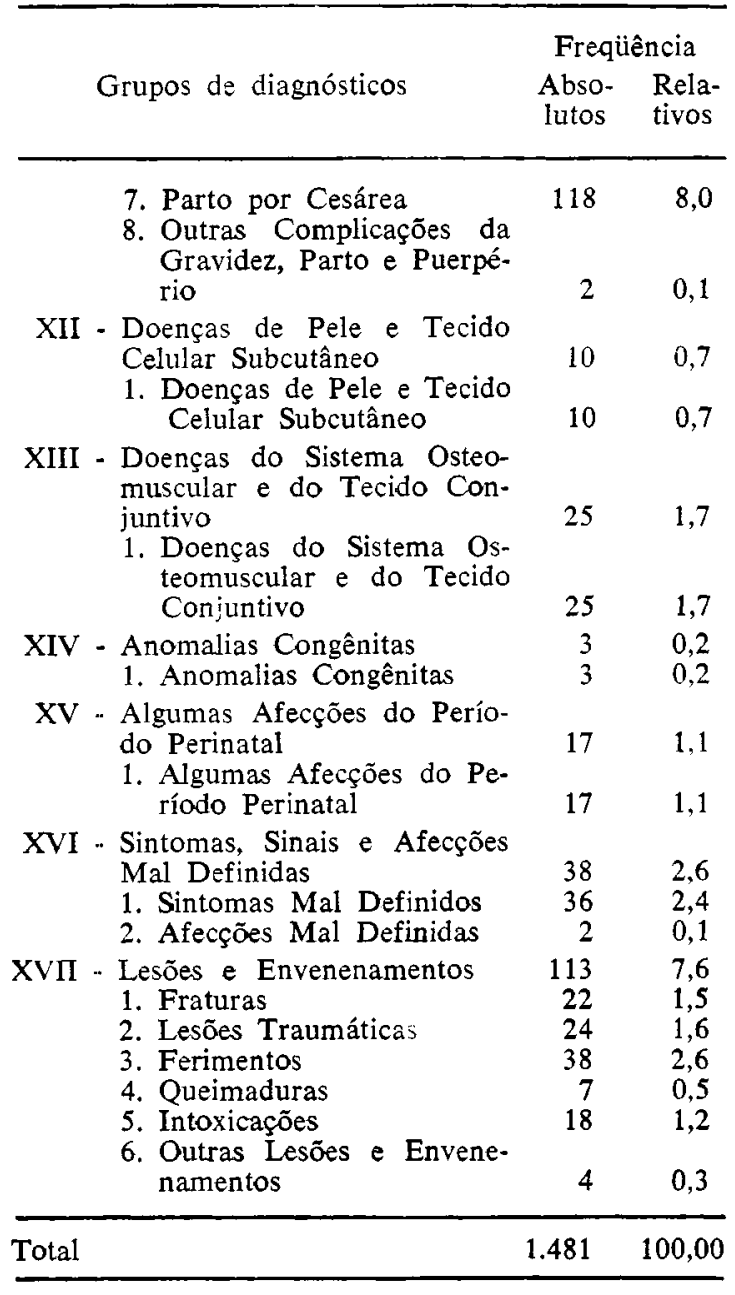

Os partos são o principal componente deste grupo, representando $17,5 \%$ do total de internações em Cubatão. $\mathrm{Na}$ análise da morbidade, os partos normais poderiam ser excluídos do total de internações. Neste caso, o grupo das causas relacionadas à gravidez cairia para $15,6 \%$ das saídas hospitalares, passando a ocupar o segundo posto e cedendo o primeiro para as Doenças do Aparelho Respiratório. No entanto, como as estatísticas de morbidade são importantes também para a avaliação e planejamento dos serviços, costuma-se incluir os partos normais na análise da morbidade hospitalar. Este procedimento foi também adotado neste estudo.

No grupo das Complicações da Gravidez, do Parto e do Puerpério, o total de partos representou $74,0 \%$ sendo $40,3 \%$ partos normais e $33,7 \%$ partos por cesáreas. No Estado, - total dos partos representava $77,3 \%$ das internações de gestantes, sendo $51,2 \%$ devidos a partos normais e $26,1 \%$ a cesáreas. Portanto, Cubatão diferencia-se do Estado por ter menor proporção de internações por partos normais e maior de cesáreas, o que junto às demais complicações se reflete numa menor proporção de partos no total.

A importância das cesáreas em Cubatão fica mais evidente através da análise da taxa de cesáreas: com uma taxa de $45,5 \%$ cesáreas por cem partos, Cubatão encontra-se muito acima da taxa do Estado de São Paulo, em $1980(22,0 \%)$ e a dos Estados Unidos, em $1980(16,5 \%)^{7}$.

Esta taxa de cesáreas pode ser decorrente de dois fenômenos: uma estratégia dos serviços de saúde ou uma maior freqüência de patologias na gravidez.

Analisando-se as taxas de cesáreas segundo as fontes pagadoras, observa-se que o predomínio do INAMPS nessas internações faz com que sua taxa de cesáreas $(44,4 \%)$ seja muito próxima da taxa do Município. A taxa de cesáreas nos convênios-empresa $(52,9 \%)$ e nas cooperativas médicas $(83,3 \%)$ foi bem mais alta que no INAMPS, fenômeno que acontece também no conjunto do Estado. Nenhuma paciente indigente fez cesárea em Cubatão.

Contudo, as taxas de cesáreas de Cubatão são bem mais elevadas que as do Estado, onde os pacientes do INAMPS tiveram uma taxa de $34,1 \%$, as medicinas de grupo, $39,7 \%$, as próprias empresas, $37,4 \%$ e as cooperativas médicas, $54,5 \%$.

A comparação das taxas de cesárea põe em evidência dois fatos: primeiro, em ambos os casos, as taxas variam segundo a fonte pagadora, mostrando que há uma influência do sistema de atendimento sobre a incidência de cesáreas $^{3}$; segundo, para as mesmas fontes pagadoras, Cubatão tem taxas mais altas que o Estado, levando a supor que a elevada frequiência de cesáreas no Município pode decorrer também de outros fatores, em especial da incidência de patologia na gravidez.

Pela Tabela 2 observa-se que em Cubatão a frequiência de aborto, hemorragias na gravidez, parto e puerpério e trabalho de parto prematuro ou falso é mais elevada do que no Estado. Estes dados mostram a necessidade de realização de estudos específicos que avaliem o desenvolvimento de patologias durante a gravidez na população de Cubatão e investiguem os fatores etiológicos a elas associados.

As Doenças do Aparelho Respiratório são muito mais frequientes em Cubatão $(22,1 \%)$ do que no Estado como um todo $(14,1 \%)$. 
TABELA 2

Distribuição das Complicações da Gravidez, Parto e Puerpério. Cubatão, julho/83 e junho/84 e Estado/80.

\begin{tabular}{lrr}
\hline \multicolumn{1}{c}{ Diagnósticos } & $\begin{array}{c}\text { Cubatão } \\
\%\end{array}$ & $\begin{array}{c}\text { Estado } \\
\%\end{array}$ \\
\hline Aborto & 9,7 & 6,7 \\
Parto Normal & 40,3 & 51,2 \\
Hemorragia na Gravidez e no & 6,6 & 2,2 \\
Parto & 2,0 & 2,4 \\
Toxemia Gravídica & 6,0 & 5,0 \\
Trabalho de Parto Prematuro & 1,1 & 1,9 \\
ou Falso & 33,7 & 26,1 \\
Complicações do Puerpério & & \\
Parto por Cesárea & 0,6 & 4,5 \\
Outras Complicações da & 100,0 & 100,0 \\
\hline Gravidez, Parto e Puerpério & & \\
\hline Total &
\end{tabular}

Apesar desta diferença, elas ocupam, em ambos os casos, o segundo posto entre as hospitalizaçōes.

A principal doença respiratória em Cubatão, como no Estado, é a pneumonia. Mas esta é muito mais freqüente em Cubatão, pois representa aí $83,5 \%$ das doenças respiratórias e $18,4 \%$ do total de internações, enquanto no Estado representa, respectivamente, $53,2 \%$ e $7,5 \%$.

Outras doenças respiratórias de importância nas internações de Cubatão são a asma ( $8,5 \%$ das doenças respiratórias) e a bronquite aguda, crônica ou sem especificação $e$ bronquiolite aguda $(2,4 \%)$. Juntas, elas representam $11,0 \%$ das internações por doenças respiratórias, ou seja, têm uma freqüuência menor que a observada no Estado de São Paulo em $1980(23,2 \%)$.

A elevada frequiência de pneumonia em Cubatão pode estar relacionada a dois tipos de problemas: por um lado, a uma superestimação do número de casos, decorrente da dificuldade de diagnóstico diferencial dentro do grupo das doenças respiratórias, e também de práticas adotadas por alguns hospitais que registram apenas um diagnóstico por paciente, subestimando os casos de patologias associadas como bronquiolite, asma, entre outras, por outro lado, póde ser também o resultado da deterioração do meio ambiente que afeta as condições de saúde da população do $\mathrm{Mul}$ nicípio de Cubatão.

Como se pode ver na Tabela 3 , a maior incidência de pneumonia é em crianças de 0 a 9 anos, porém a frequiência de casos nesse grupo etário é maior em Cubatão.
TABELA 3

Distribuição dos casos de pneumonia por grupos de idade. Cubatão, julho/83 a junho/84 e Estado/80.

\begin{tabular}{ccc}
\hline Grupos de idade & $\begin{array}{c}\text { Cubatão } \\
\%\end{array}$ & $\begin{array}{c}\text { Estado } \\
\%\end{array}$ \\
\hline $0-9$ & 73,3 & 63,6 \\
$10-17$ & 7,0 & 7,2 \\
$18-64$ & 16,8 & 21,1 \\
+65 & 2,9 & 8,1 \\
\hline Total & 100,0 & 100,0 \\
\hline
\end{tabular}

Dos três hospitais gerais do Município, aquele que concentra maior número de casos de pneumonia $(61,9 \%)$ é o que atende mais crianças. Coincidentemente, esse hospital costuma registrar apenas um diagnóstico, a que aumenta a possibilidade de superestimação da pneumonia.

Por sua vez, a asma, que é a segunda doença respiratória em Cubatão, apresenta a seguinte distribuição por idade: $46,4 \%$ de 0 a 9 anos, 3,6\% de 10 a 17 anos e $50,0 \%$ de 18 anos em diante.

Comparando-se a distribuição da pneumonia e da asma por faixa etária nota-se que há uma maior concentração de adultos nesta última, o que sugere a interferência de fatores sensibilizantes no ambiente de trabalho.

Quanto à bronquite, a concentração de casos em crianças é menor em Cubatão $(41,66 \%)$ do que no Estado $(44,35 \%)$, talvez devido ao problema apontado de vício de diagnóstico que superestima a pneumonia.

O elevado percentual de Doenças do Aparelho Respiratório como causa de internação $(22,1 \%)$ e como causa de morte $(10,0 \%$ da mortalidade geral e $19,0 \%$ da mortalidade de menores de 1 ano, em 1983), mostra que elas representam um grave problema de saúde pública em Cubatão.

Cubatão destaca-se por ter elevado índice de poluição ambiental. Nesse Município foram identificados 75 poluentes de diferentes tipos, dentre os quais: material particulado, substâncias irritantes e alergênicas" com baixo índice de saneamento $e$, como foi colocado anteriormente, grande parte da população residindo em favelas. Estes fatores, em conjunto, poderiam ser responsáveis pelo surgimento e agravamento das doenças respiratórias.

A alta incidência de doenças respiratórias contrasta com a falta de aparelhamento dos 
serviços de saúde do Município para seu atendimento: até dezembro de 1983 não havia nenhum leito de terapia intensiva e nenhum ambulatório de pneumologia na rede de serviços públicos de Cubatão.

Diante desta situação fica evidente que os serviços de saúde pública de Cubatão devem adotar o problema das doenças respiratórias como um de seus objetos primordiais de atuação. O aparelhamento dos serviços básicos para $O$ atendimento ambulatorial dessas patologias contribuiria, sem dúvida, para evitar o agravamento de $\operatorname{casos}^{8}$, o que deveria estar aliado ao desenvolvimento de política de melhoria das condições ambientais: saneamento, poluição, condições de trabalho.

Com um percentual de $10,5 \%$, as Doenças das Gdândulas Endócrinas, da Nutrição e do Metabolismo e Transtornos Imunitários são a terceira causa de internação. Esta participação elevada contrasta com o que foi observado no Estado de São Paulo, onde elas ocupavam o nono posto, com $3,7 \%$, apenas, das hospitalizações. Esta diferença deve-se à maior incidência de desidratações em Cubatão (Tabela 4).

\section{TABELA 4}

Distribuição dos diagnósticos das Doenças das Glândulas Endócrinas, da Nutrição e do Metabolismo e Transtornos Imunitários. Cubatão, julho/83 a junho/84 e Estado/80.

\begin{tabular}{lrr}
\hline \multicolumn{1}{c}{ Diagnósticos } & $\begin{array}{c}\text { Cubatão } \\
\%\end{array}$ & $\begin{array}{c}\text { Estado } \\
\%\end{array}$ \\
\hline Transtornos da Glândula Tireóide & 1,3 & 5,8 \\
Diabetes Mellitus & 8,4 & 15,6 \\
Deficiências Nutricionais & 3,2 & 7,9 \\
Transtornos do Equilíbrio & & \\
Hidroeletrolítico e & & \\
Ácido-Básico & 86,5 & 66,4 \\
Outras Doenças Endócrinas & 0,6 & 4,3 \\
Total & 100,0 & 100,0 \\
\hline
\end{tabular}

Embora possam haver fatores epidemiológicos contribuindo para que as desidratações sejam mais frequientes em Cubatão do que no conjunto do Estado, pode-se atribuir parte de sua importância a vícios no registro dos dados. Com efeito, um dos hospitais do Município costuma registrar apenas um diagnóstico. No caso, por exemplo, da desidratação associada com diarréia, registrar-se-ia apenas a desidratação. Este procedimento poderia estar subestimando o peso das Doenças Infecciosas e Parasitárias na morbidade hospitalar do Município (onde, com 2,57\% das internações, elas ocupam o nono lugar) e superestimando o peso das desidratações e do grupo de diagnósticos no qual estão incluídas.

De fato, o hospital em questão faz exatamente 0 inverso daquilo que Lebrão $0^{5}$ recomendava fosse feito para que se pudesse avaliar corretamente o peso das diarréias na morbidade, isto é, que as desidratações fossem agrupadas às Doenças Infecciosas e Parasitárias à medida em que elas são, na maioira das vezes, decorrentes de infecções intestinais. Admitindo-se que todas as desidratações ocorridas em Cubatão fossem decorrentes de Infecções Intestinais Mal Definidas, poder-se-ia agregá-las a estas, que passariam, então, a representar $11,1 \%$ das internações. Neste caso, o grupo das Doenças Infecciosas e Parasitárias como um todo passaria de $2,6 \%$ para $11,6 \%$ das internações em Cubatão, ou seja, passaria a representar a terceira causa na morbidade hospitalar do Município.

Em Cubatão, como no Estado em seu conjunto, a maioria dos casos de desidratação ocorre com crianças.

Finalmente, cabe observar que se houvesse serviços ambulatoriais próximos aos locais de moradia, talvez o número de casos de internações por desidratação fosse menor pela prevenção ou tratamento precoce da patologia que o desencadeou.

As Doenças do Aparelho Circulatório foram a quarta causa com $10,5 \%$ das internações, não diferindo da posição ocupada no Estado, e apresentando frequiência semelhante à deste $(11,0 \%)$.

Em relação ao total dos casos de doenças circulatórias, a doença hipertensiva foi a causa mais freqüente, com $35,5 \%$. As doenças da circulação pulmonar e outras formas de doenças do coração (doença pulmonar aguda, outras doenças da circulação pulmonar, endocardite aguda e subaguda, cardimiopatias, arritmias cardíacas, insuficiência cardíaca e denominações e complicações mal definidas de doenças do coração) representaram $29,6 \%$; as doenças das veias $13,15 \%$, a doença cerebrovascular $10,5 \%$ e a doença isquêmica do coração, 7,9\%. Comparando-se esta distribuição com a do Estado, observa-se que as doenças hipertensivas são mais frequientes em Cubatão que no Estado onde ocuparam o terceiro posto com $19,3 \%$, enquanto que as doenças da circulação pulmonar e outras formas de doenças do coração ficaram no primeiro posto $(33,2 \%)$ no Estado. 
Embora a morbidade hospitalar não reflita diretamente a morbidade da população, podese atribuir esta diferença na distribuição interna de diagnósticos das doenças cardiovasculares à estrutura etária da população de Cubatão, onde a pequena proporção de idosos poderia estar explicando a menor proporção de doenças cujo aparecimento está associado ao envelhecimento. Mas também não se pode afastar a hipótese, que poderia ser melhor estudada, da relação dessas doenças com as substâncias químicas utilizadas no processo de produção.

Outro aspecto a destacar é a diferença que as Doenças do Aparelho Circulatório apresentam na morbidade hospitalar e na mortalidade geral de Cubatão, corroborando o que já foi observado em outros trabalhos, isto é, as diferenças existentes entre o perfil da morbidade e o da mortalidade de cada população. No perfil da morbidade hospitalar a patologia mais freqüente é a hipertensão arterial, sendo que dentre as Doenças do Aparelho Circulatório, as Doenças Isquêmicas do Coração são responsáveis pelo maior número de mortes. A constatação desta diferença mostra, mais uma vez, que estudos de mortalidade e de morbidade hospitalar se completam na medida em que captam dimensões diferentes do estado de saúde da população.

As lesões e envenenamentos foram a quinta causa de internações em Cubatão, com $7,6 \%$, destacando-se por serem mais freqüentes do que no Estado onde, com 5,8\% das saídas, eram a sétima causa em 1980 . Note-se que os dados de morbidade hospitalar podem estar subestimados devido a que muitos acidentes são atendidos em Pronto Socorro, sem que seja necessária uma internação.

As causas mais frequientes são os ferimentos e lesões traumáticas dos vasos sangüíneos (33,6\% do total de lesões e envenenamentos), seguidos das fraturas (com 19,5\%). Os envenamentos representam $15,9 \%$, as outras lesões e complicações imediatas de traumatis- mos, $11,5 \%$, as lesões intracranianas incluindo nervos, $10,6 \%$, as queimaduras, $6,2 \%$.

Esta distribuição das causas em Cubatão difere bastante da do Estado onde as fraturas (com 30,5\%), as lesões intracranianas (com $18,9 \%$ ) e as outras lesões e complicaçōes de traumatismos (com 17,1\%) são as causas mais frequientes. Por outro lado, em Cubatão ocorrem muito mais casos de envenenamentos e queimaduras do que no Estado onde estas causas representam, respectivamente, $9,0 \%$ e $3,8 \%$.

Estas particularidades das lesões e envenenamentos podem estar relacionadas com os altos níveis de acidentes de trabalho apresentados por Cubatão, pois Faria ${ }^{7}$ observou que as consequiências mais frequientes dos acidentes de trabalho no Município de Cubatão, em 1980, foram: contusões, cortes, queimaduras, mal jeito na coluna e atropelamento.

Esta hipótese reforça-se na medida em que se observa uma concentração de casos na idade produtiva, conforme a Tabela 5, embora não se possa reduzir todas as ocorrências a acidentes de trabalho.

As Doenças do Aparelho Geniturinário foram a sexta causa de internação em Cubatão, com $7,6 \%$ das saídas hospitalares. Neste caso Cubatão não se diferencia muito do Estado, onde estas doenças representaram 7,3\% e ocuparam o quinto posto.

No entanto, os tipos de doenças predominantes são diferentes. Em Cubatão predominam as doenças dos órgãos genitais femininos, com $62,5 \%$, enquanto no Estado estas doenças representaram apenas $40,7 \%$, precedidas pelas doenças do aparelho urinário $(46,1 \%)$.

Dentre as doenças dos órgãos genitais femininos destacam-se os transtornos não inflamatórios dos órgãos pélvicos, com $23,2 \%$ do grupo das doenças geniturinárias, e os transtornos inflamatórios dos órgãos pélvicos, com $14,3 \%$.

TABELA 5

Distribuição das lesões e envenenamentos segundo faixas etárias. Cubatão, julho/83 a junho/84.

\begin{tabular}{lcccccc}
\hline Diagnósticos & $\begin{array}{c}0-9 \\
\%\end{array}$ & $\begin{array}{c}10-17 \\
\%\end{array}$ & $\begin{array}{c}18-49 \\
\%\end{array}$ & $\begin{array}{c}50-64 \\
\%\end{array}$ & $\begin{array}{c}+65 \\
\%\end{array}$ & $\begin{array}{c}\text { Total } \\
\text { e }\end{array}$ \\
\hline Total & 13,3 & 5,3 & 68,1 & 8,0 & 5,3 & 100,0 \\
Ferimentos & 18,4 & 5,3 & 57,9 & 7,9 & 10,5 & 100,0 \\
Fraturas & 13,6 & 9,1 & 59,1 & 13,6 & 4,6 & 100,0 \\
Envenenamentos & 5,6 & - & 88,9 & 5,6 & - & 100,0 \\
\hline
\end{tabular}


O peso das doenças dos 6́rgãos genitais femininos nesse grupo faz com que as mulheres representem parcela ainda maior desses pacientes em Cubatão $(82,1 \%)$ que no Estado $(65,2 \%)$.

A elevada incidência de distúrbios ginecológicos em Cubatão, observada pela pesquisa, deveria merecer estudo especial.

Em sétimo posto na morbidade hospitalar de Cubatão encontram-se as doenças do aparelho digestivo com $7,2 \%$ dos hospitalizados. Também neste caso Cubatão não se diferencia muito do Estado, no qual estas doenças se encontram como sexta causa com $6,7 \%$ das internações.

As doenças que compõem este grupo distribuem-se nas seguintes proporções: hérnia $(28,3 \%)$; doenças do e stômago e duodeno $(23,6 \%)$; gastroenterocolite não-infecciosa $(10,4 \%)$; colelitíase $(9,4 \%)$; outras doenças do aparelho digestivo $(9,4 \%)$; apendicite $(7,5 \%)$ e doença do fígado $(7,5 \%)$.

Destacam-se nesse grupo as doenças crônicas do fígado e cirrose que apresentaram maior percentual em Cubatão $(5,7 \%)$ do que no Estado $(3,9 \%)$, apontando para a necessidade de estudos especiais sobre suas causas.

As Doenças Infecciosas e Parasitárias representaram, apenas, $2,6 \%$ das internaçōes de Cubatão, ocupando o oitavo posto. Estes baixos valores contrastam com a posição e a frequiência destas doenças no Estado onde representavam $7,8 \%$ da morbidade hospitalar, situando-se como quarta causa.

A baixa representatividade provavelmente se deveu a subestimaçōes dos casos de doenças infecciosas intestinais em Cubatão conforme foi analisado na apresentação dos dados do grupo III.

Apesar de sua subestimação, as doenças infecciosas intestinais foram a principal causa neste grupo, com $81,6 \%$ destas internações e situaram-se no mesmo patamar de freqüûncia que foi observado no Estado (onde representavam $80,7 \%$ das doenças infecciosas e parasitárias). Outras causas que se destacam neste capítulo, em Cubatão, são: erisipela, com $13,2 \%$ e as doenças virais, com 5,3\%. Observe-se que, no Estado, as doenças virais tiveram frequêencia mais elevada: $8,3 \%$.

Os Sintomas, Sinais e Afecções Mal Definidas também ocuparam o oitavo posto na morbidade hospitalar de Cubatão, com 2,6\% das internações. Estes diagnósticos foram me- nos frequientes em Cubatão do que no Estado, onde, apesar de também ocuparem o oitavo posto, elas representaram $5,6 \%$.

$O$ fato de ter havido maior participação do INAMPS no pagamento das internaçōes em Cubatão $(87,7 \%)$ do que no Estado $(60,0 \%)$ pode ser a explicação para a menor proporção de diagnósticos mal definidos, pois o INAMPS exige, em geral, diagnóstico preciso para pagar $o$ atendimento.

Esta hipótese se reforça quando se observa que a frequiência de diagnósticos mal definidos em pacientes do INAMPS é bem menor $(2,5 \%)$ do que, por exemplo, em pacientes gratuitos $(7,7 \%)$ em Cubatão.

Em conjunto, todas as outras causas representaram, apenas, $6,1 \%$ das internações de Cubatão, ou seja, bem menos do que os $10,3 \%$ que representavam no Estado, em 1980.

Entre estas causas destacam-se as doenças do sistema nervoso e os neoplasmas, por apresentarem frequiências bem inferiores às do Estado como um todo. Estes valores devem estar refletindo muito mais a precariedade dos serviços de saúde do Município do que a incidência dessas doenças.

Além das doenças do sistema nervoso e dos neoplasmas, são baixas também as freqüências de casos de doenças do sistema osteomuscular e de anomalias congênitas. E possível que as baixas incidências destas quatro causas se devam à emigração de pacientes, que saem para buscar atendimento médico em outros municípios. Lebrão ${ }^{5}$ já havia observado esse fenômeno no Vale do Paraíba, justamente para essas doenças, que necessitam de uma maior complexidade de aparelhos de diagnóstico ou de sistemas de registro especializados para o conhecimento de sua incidência.

\section{Distribuição da Morbidade por Grupos Etários}

Analisando as saídas dos diferentes grupos etários em relação ao total das internaçōes do Município de Cubatão, obtemos a seguinte distribuição: $27,6 \%$ de 0 a 9 anos; $5,3 \%$ de 10 a 17 anos; $60,9 \%$ de 18 a 64 anos e $6,1 \%$ de mais de 65 anos. Comparando estes resultados com o Estado de São Paulo, percebemos que $\circ$ grupo etário de 0 a 9 anos teve participação mais elevada em Cubatão do que no Estado $(19,2 \%)$. Já os pacientes com mais de 60 anos tiveram maior peso nas internações do Estado de São Paulo (12,8\%). 
Com a finalidade de percebermos as doenças mais comuns nas hospitalizações para os grupos etários foram efetuadas tabelas para cada faixa etária.

No grupo de 0 a 9 anos (Tabela 6) as doenças respiratórias apareceram em primeiro lugar, sendo que em Cubatão foram responsáveis por mais da metade $(53,5 \%)$ das hospitalizações, enquanto este percentual para 0 Estado foi de $39,1 \%$, o que reafirma a importância destas doenças no Município. As doenças respiratórias, as doenças infecciosas e as doenças das glândulas endócrinas, da nutrição e do metabolismo e transtornos imunitários (o que equivale a dizer as desidratações) corresponderam a $83,1 \%$ das hospitalizações do grupo de 0 a 9 anos em Cubatão. No Estado, essas mesmas causas corresponderam a $69,7 \%$. Os três grupos citados estão classicamente relacionados às condições de habitação, alimentação e saneamento básico, o que mostra que o desenvolvimento industrial do Município não concorreu para melhorar as condições de vida de seus habitantes.

\section{TABELA 6}

Distribuição dos diagnósticos no grupo de 0 a 9 anos. Cubatão, julho/83 a junho/84, Estado/80.

\begin{tabular}{|c|c|c|c|c|}
\hline \multirow{2}{*}{ Diagnósticos } & \multicolumn{2}{|c|}{ Cubatão } & \multicolumn{2}{|c|}{ Estado de São Paulo } \\
\hline & $\%$ & Posto & & Posto \\
\hline Doenças Infecciosas & 4,7 & $3 .^{\circ}$ & 22,8 & $2 .^{\circ}$ \\
\hline Neoplasias & 0 & - & 0,9 & $12^{\circ}$ \\
\hline Doenças Endócrinas e Transtornos Metabólicos & 24,9 & $2 .^{\circ}$ & 7,8 & $3 .^{\circ}$ \\
\hline Doenças do Sangue & 0,7 & $100^{\circ}$ & 0,8 & $13 .^{\circ}$ \\
\hline Transtornos Mentais & 0 & - & 0,1 & $15 .^{\circ}$ \\
\hline Doenças do Sistema Nervoso e Órgãos dos Sentidos & 0 & - & 2,2 & $99^{\circ}$ \\
\hline Doenças do Aparelho Circulatório & 0 & - & 0,9 & $12 .^{\circ}$ \\
\hline Doenças do Aparelho Respiratório & 53,6 & $10^{\circ}$ & 39,1 & $10^{\circ}$ \\
\hline Doenças do Aparelho Digestivo & 2,7 & $6 .^{\circ}$ & 3,6 & $7 .^{\circ}$ \\
\hline Doenças do Aparelho Geniturinário & 1,5 & $8 .^{\circ}$ & 4,0 & $6 .^{\circ}$ \\
\hline Doenças da Pele & 0,2 & $12 .^{\circ}$ & 0,8 & $13 .^{\circ}$ \\
\hline Doenças do Aparelho Osteomuscular & 1,0 & $9 .^{\circ}$ & 0,7 & $14 .^{\circ}$ \\
\hline Anomalias Congênitas & 0,5 & $11 .^{\circ}$ & 2,0 & $100^{\circ}$ \\
\hline Cautsas Perinatais & 4,2 & $4 .^{\circ}$ & 3,3 & $8 .^{\circ}$ \\
\hline Doenças Mal Definidas & 2,4 & $7 .^{\circ}$ & 4,8 & $5 .^{\circ}$ \\
\hline Lesões e Envenenamentos & 3,7 & $5 .^{\circ}$ & 5,1 & $4 .^{\circ}$ \\
\hline Outros motivos & 0 & 一 & 1,1 & $11 .^{\circ}$ \\
\hline Total & 100,0 & - & 100,0 & - \\
\hline
\end{tabular}

O grupo de 10 a 17 anos (Tabela 7) representou $5,3 \%$ do total das hospitalizações. As causas mais importantes foram as doenças respiratórias $(25,3 \%)$, as complicações da gravidez, parto e puerpério $(21,5 \%)$, as doenças do aparelho geniturinário $(11,4 \%)$, as doenças do aparelho digestivo $(10,1 \%)$ e as lesões e envenenamentos $(7,6 \%)$. Também aqui as doenças respiratórias destacam-se em relação às demais causas de internação, quando comparadas ao Estado $(13,4 \%)$. As complicações de gravidez, parto e puerpério, apesar de menos freqüentes do que no Estado $(32,8 \%)$, apareceram como problema importante neste grupo etário. As doenças do aparelho geniturinário e do aparelho digestivo ocuparam o terceiro e quarto postos em Cubatāo, diferindo do Estado em que estes foram ocupados pelas lesões e envenenamentos e pelas doenças infecciosas.

O padrão de distribuição das patologias em relação às saídas hospitalares do grupo de 18 a 64 anos de Cubatão e do Estado de São Paulo são semelhantes (Tabela 8). De 18 a 49 anos as causas mais frequientes foram as complicações de gravidez, parto e puerpério, doenças do aparelho geniturinário, lesões e envenenamentos, doenças do aparelho circulatório e doenças do aparelho digestivo. Em Cubatão, o terceiro posto deste grupo etário foi ocupado pelas lesões e envenenamentos $(10,0 \%)$, o que poderia ser explicado pelas características industriais do Município $0^{7,10}$. De 50 a 64 anos as patologias que provocaram mais internações compreenderam os seguintes grupos: doenças do aparelho circulatório, res- 
TABELA 7

Distribuição dos diagnósticos do grupo de 10 a 17 anos Cubatão, julho/83 a junho/84.

\begin{tabular}{|c|c|c|c|c|}
\hline \multirow[t]{2}{*}{ Diagnósticos } & \multicolumn{2}{|c|}{$\begin{array}{l}\text { Cubatão } \\
\text { (10 a } 17 \text { anos) }\end{array}$} & \multicolumn{2}{|c|}{$\begin{array}{l}\text { Estado de São Paulo } \\
\quad(10 \text { a } 19 \text { anos })\end{array}$} \\
\hline & $\%$ & Posto & $\%$ & Posto \\
\hline Doenças Infecciosas & 0 & - & 6,9 & $4 .^{\circ}$ \\
\hline Neoplasias & 0 & 一 & 1,4 & $11 .^{\circ}$ \\
\hline Doenças Endócrinas e Transtornos Metabólico & 3,8 & $7 .^{\circ}$ & 2,9 & $9 .^{\circ}$ \\
\hline Doenças do Sangue & 0 & - & 0,4 & $15 .^{\circ}$ \\
\hline Transtornos Mentais & 1,3 & $8 .^{\circ}$ & 0,6 & $14 .^{\circ}$ \\
\hline Doenças do Sistema Nervoso e Órgãos dos Sentidos & 3,8 & $7 .^{\circ}$ & 2,6 & $10 .^{\circ}$ \\
\hline Doenças do Aparelho Circulatório & 3,8 & $7 .^{\circ}$ & 2,6 & $10 .^{\circ}$ \\
\hline Doenças do Aparelho Respiratório & 25,3 & $1 .^{\circ}$ & 13,4 & $2 .^{\circ}$ \\
\hline Doenças do Aparelho Digestivo & 10,1 & $4 .^{\circ}$ & 5,8 & $7 .^{\circ}$ \\
\hline Doenças do Aparelho Geniturinário & 11,4 & $3 .^{\circ}$ & 6,4 & $5 .^{\circ}$ \\
\hline Complicações da Gravidez, Parto e Puerpério & 21,6 & $2 .^{\circ}$ & 32,8 & $1 .^{\circ}$ \\
\hline Doenças da Pele & 1,3 & $8 .^{\circ}$ & 1,6 & $13 .^{\circ}$ \\
\hline Doenças do Aparelho Osteomuscular & 6,3 & $6 .^{\circ}$ & 2,6 & $10 .^{\circ}$ \\
\hline Anomalias Congênitas & 0 & - & 1,2 & $12 .^{\circ}$ \\
\hline Doenças Mal Definidas & 3,8 & $7 .^{\circ}$ & 6,2 & $6 .^{\circ}$ \\
\hline Lesões e Envenenamentos & 7,6 & $5 .^{\circ}$ & 10,1 & $3 .^{\circ}$ \\
\hline Outros motivos & 0 & - & 3,1 & $8 .^{\circ}$ \\
\hline Total & 100,0 & - & 100,0 & - \\
\hline
\end{tabular}

TABELA 8

Distribuição dos diagnósticos do grupo de 18 a 49 e 50 a 64 anos. Cubatão, julho/83 a junho/84.

\begin{tabular}{|c|c|c|c|c|c|c|c|c|}
\hline \multirow[t]{2}{*}{ Diagnósticos } & \multicolumn{2}{|c|}{$\begin{array}{c}\text { Cubatão } \\
(18 \text { a } 49 \text { anos })\end{array}$} & \multicolumn{2}{|c|}{$\begin{array}{l}\text { Est. de } S \text {. Paulo } \\
(20 \text { a } 49 \text { anos })\end{array}$} & \multicolumn{2}{|c|}{$\begin{array}{c}\text { Cubatão } \\
(50 \text { a } 64 \text { anos })\end{array}$} & \multicolumn{2}{|c|}{$\begin{array}{l}\text { Est. de S. Paulo } \\
\text { (50 a } 59 \text { anos) }\end{array}$} \\
\hline & $\%$ & Posto & & Posto & $\%$ & Posto & $\%$ & Posto \\
\hline Doenças Infecciosas & 1,3 & $90^{\circ}$ & 3,6 & $9 .^{\circ}$ & 3,8 & $8 .^{\circ}$ & 5,5 & $7 .^{\circ}$ \\
\hline Neoplasias & 0,8 & $11 .^{\circ}$ & 2,3 & $10 .^{\circ}$ & 0 & - & 7,6 & $5 .^{\circ}$ \\
\hline \multicolumn{9}{|l|}{ Doenças Endócrinas e } \\
\hline Transtornos Metabólicos & 3.8 & $7 .^{\circ}$ & 1,9 & $12 .^{\circ}$ & 9,1 & $4 .^{\circ}$ & 4,7 & $9 .^{\circ}$ \\
\hline Doenças do Sangue & 0,7 & $12 .^{\circ}$ & 0,4 & $17 .^{\circ}$ & 0 & 一 & 0 & 一 \\
\hline Transtornos Mentais & 0,7 & $12 .^{\circ}$ & 0,9 & $14 .^{\circ}$ & 1,5 & $9 .^{\circ}$ & 1,2 & $12 .^{\circ}$ \\
\hline $\begin{array}{l}\text { Doenças do Sistema Ner- } \\
\text { voso e Orgãos dos Sentidos }\end{array}$ & 0,4 & $13 .^{\circ}$ & 1,6 & $13 .^{\circ}$ & 1,5 & $9 .^{\circ}$ & 3,3 & $10 .^{\circ}$ \\
\hline Doenças do Aparelho & & & & & & & & \\
\hline $\begin{array}{l}\text { Circulatório } \\
\text { Doenças do Aparelho }\end{array}$ & 9,2 & $4 .^{\circ}$ & 7,7 & $3 .^{\circ}$ & 32,6 & $1 .^{\circ}$ & 26,3 & $1 .^{\circ}$ \\
\hline $\begin{array}{l}\text { Respiratório } \\
\text { Doenças do Aparelho }\end{array}$ & 7,3 & $6 .^{\circ}$ & 5,9 & $5 .^{\circ}$ & 15,9 & $2 .^{\circ}$ & 10,1 & $30^{\circ}$ \\
\hline $\begin{array}{l}\text { Digestivo } \\
\text { Doenças do Aparelho }\end{array}$ & 7,5 & $50^{\circ}$ & 7,0 & $4 .^{\circ}$ & 13,6 & $3 .^{\circ}$ & 11,3 & $2 .^{\circ}$ \\
\hline $\begin{array}{l}\text { Geniturinário } \\
\text { Complicações da Gravidez, }\end{array}$ & 10,8 & $2 .^{\circ}$ & 8,9 & $2 .^{\circ}$ & 5,3 & $6 .^{\circ}$ & 9,4 & $4 .^{\circ}$ \\
\hline Parto e Puerpério & 43,1 & $1 .^{\circ}$ & 41,0 & $1 .^{\circ}$ & 0,8 & $10 .^{\circ}$ & 0,1 & $15^{\circ}$ \\
\hline Doenças da Pele & 0,7 & $12 .^{\circ}$ & 0,8 & $15 .^{\circ}$ & 0,8 & $100^{\circ}$ & 1,0 & $13 .^{\circ}$ \\
\hline Doenças do Aparelho & & & & & & & & \\
\hline Osteomuscular & 1,2 & $100^{\circ}$ & 1,9 & $11 .^{\circ}$ & 4,6 & $7 .^{\circ}$ & 3,2 & $11^{\circ}$ \\
\hline Anomalias Congênitas & 0,1 & $14 .^{\circ}$ & 0,5 & $16 .^{\circ}$ & 0 & - & 0,8 & $14 .^{\circ}$ \\
\hline Doenças Mal Definidas & 2,6 & $8 .^{\circ}$ & 5,7 & $6 .^{\circ}$ & 3,8 & $8 .^{\circ}$ & 6,6 & $6 .^{\circ}$ \\
\hline Lesões e Envenenamentos & 10,0 & $3 .^{\circ}$ & 5,7 & $7 .^{\circ}$ & 6,8 & $5 .^{\circ}$ & 5,2 & $8 .^{\circ}$ \\
\hline Outros motivos & 0 & 一 & 4,4 & $8 .^{\circ}$ & 0 & - & 3,2 & $11^{\circ}$ \\
\hline Total & 100,0 & - & 100,0 & - & 100,0 & 一 & 99,5 & - \\
\hline
\end{tabular}


piratório e digestivo. Não houve casos de neoplasias neste grupo etário.

No grupo de 65 anos e mais (Tabela 9) as doenças do aparelho circulatório destacaramse, representando a terça parte das hospitalizações. Em segundo posto apareceram as doenças respiratórias e doenças do aparelho digestivo. Neste grupo etário as doenças das glândulas endócrinas, da nutrição e do metabolismo e transtornos imunitários representaram
9,9\% das internações, compreendendo principalmente as desidratrações e o diabetes. A discrepância mais uma vez encontrada nos percentuais de neoplasias entre o Município $(2,2 \%)$ e o Estado $(7,7 \%)$ deve estar relacionada à falta de serviços especializados já comentada anteriormente. Os sintomas, sinais e afecções mal definidos que foram a quinta causa de hospitalização no Estado não ocorreram em Cubatão.

TABELA 9

Distribuição dos diagnósticos do grupo de 65 anos e mais. Cubatão, julho/83 a junho/84.

\begin{tabular}{|c|c|c|c|c|}
\hline \multirow{2}{*}{ Diagnósticos } & \multicolumn{2}{|c|}{$\begin{array}{c}\text { Cubatão } \\
(+\quad 65 \text { anos })\end{array}$} & \multicolumn{2}{|c|}{$\begin{array}{c}\text { Estado de São Paulo } \\
(+60 \text { anos })\end{array}$} \\
\hline & $\%$ & Posto & 90 & Posto \\
\hline Doenças Infecciosas & 4,4 & $6 .^{\circ}$ & 4,4 & $8 .^{\circ}$ \\
\hline Neoplasias & 2,2 & $8 .^{\circ}$ & 7,7 & $4 .^{\circ}$ \\
\hline Doenças Endócrinas e Transtornos Metabólicos & 9,9 & $3 .^{\circ}$ & 4,8 & $79^{\circ}$ \\
\hline Doenças do Sangue & 0 & - & 0,8 & $12 .^{\circ}$ \\
\hline Transtornos Mentais & 0 & - & 0,8 & $12 .^{\circ}$ \\
\hline Doenças do Sistema Nervoso e Órgãos dos Sentidos & 3,3 & $7 .^{\circ}$ & 3,3 & $9 .^{\circ}$ \\
\hline Doenças do Aparelho Circulatório & 38,5 & $1 .^{\circ}$ & 36,3 & $1 .^{\circ}$ \\
\hline Doenças do Aparelho Respiratório & 12,1 & $2 .^{\circ}$ & 11,5 & $2 .^{\circ}$ \\
\hline Doenças do Aparelho Digestivo & 12,1 & $2 .^{\circ}$ & 8,3 & $3 .^{\circ}$ \\
\hline Doenças do Aparelho Geniturinário & 7,7 & $4 .^{\circ}$ & 5,9 & $6 .^{\circ}$ \\
\hline Doenças da Pele & 2,2 & $8 .^{\circ}$ & 0,8 & $13 .^{\circ}$ \\
\hline Doenças do Aparelho Osteomuscular & 1,1 & $9 .^{\circ}$ & 2,7 & $100^{\circ}$ \\
\hline Anomalias Congênitas & 0 & - & 0,4 & $150^{\circ}$ \\
\hline Doenças Mal Definidas & 0 & - & 6,1 & $5 .^{\circ}$ \\
\hline Lesões e Envenenamentos & 6,6 & $5 .^{\circ}$ & 4,4 & $8 .^{\circ}$ \\
\hline Outros motivos & 0 & - & 1,8 & $11 .^{\circ}$ \\
\hline Total & 100,0 & - & 100,0 & - \\
\hline
\end{tabular}

\section{Mortalidade Hospitalar}

A taxa de mortalidade hospitalar em Cubatão foi de $1,1 \%$, menor que a do Estado $(2,3 \%)$, em 1980 , e a dos hospitais gerais de Santos $(3,5 \%)$, em 1983. Ao lado disto, os dados indicam que o movimento nosocomial foi elevado, tendo cada leito hospitalar sido ocupado 41,2 vezes no período. O baixo percentual de mortalidade pode ser explicado pela ausência de serviços especializados em tratamento de pacientes graves como, também, pela escassez de recursos de diagnóstico já comentados anteriormente.

Segundo o diagnóstico, as mortes se distribuíram em apenas seis grupos da CID, apresentando equivalência com o Estado de São Paulo nos três piimeiros postos - algumas afecções originadas no período perinatal, $17,6 \%$, neoplasmas, $12,5 \%$, doenças do aparelho circulatório, $4,6 \%$. $O$ peso das duas primeiras foi maior do que no Estado $(10,9 \%$ e $9,1 \%$, respectivamente). Devido ao baixo número de mortes (17) nos hospitais, não foram efetuadas análises mais aprofundadas para evitar incorreçōes.

\section{Fontes de Financiamento}

A análise das fontes de financiamento mostra que o INAMPS foi a mais importante fonte pagadora, com $87,7 \%$ das internações, seguido do convênio-empresa com 6,0\%. Não foram encontrados pacientes particulares puros na amostra analisada e sim formas mistas de pagamento (meia pensão). O percentual de ausência de informação foi muito baixo.

A comparação dos dados do Município de Cubatão com o Estado mostra que o peso do INAMPS como fonte pagadora foi maior no primeiro. 
TABELA 10

Distribuição das internações segundo fonte de financiamento. Cubatão, julho/83 a junho/84 e Estado/80

\begin{tabular}{lrr}
\hline Fontes de financiamento & $\begin{array}{c}\text { Cubatão } \\
\%\end{array}$ & $\begin{array}{c}\text { Estado } \\
\%\end{array}$ \\
\hline INAMPS & 87,7 & 60,0 \\
Convênio Empresa & 6,0 & 7,2 \\
Gratuitos & 1,8 & 6,2 \\
Outras Previdências & 1,6 & 1,5 \\
Cooperativa Médica & 1,5 & 1,0 \\
Particular & & \\
(inclusive meia pensão) & 1,4 & 4,1 \\
FUNRURAL & 0,1 & 7,5 \\
Outros & - & 3,4 \\
Sem Informação & - & 9,1 \\
Total & 100,0 & 100,0 \\
\hline
\end{tabular}

Ao contrário, os percentuais de gratuitos e sem informação foram muito baixos, o que indica uma clientela empregada ou segurada pela Previdência Social (Tabela 10).

\section{AGRADECIMENTOS}

À Zélia Maria de Oliveira, do Instituto de Saúde, e à Dra. Eunice Pinho de Castro e Silva, do Departamento de Epidemiologia da Faculdade de Saúde Pública que determinaram a amostra utilizada; ao Antonio de Castro Bruni da Divisão de Modelagem, Estatística e Meteorologia da Companhia de Tecnologia de Saneamento Ambiental (CETESB), pela programação para processamento de dados; e ao Dr. Cecil Coelho Junior da Coordenadoria de Assistência Hospitalar pelo fornecimento dos Boletins CAH-101.

ROCHA, L. E. et al. [Comparative data on hospital morbidity in Cubatão and the State of S. Paulo, Brazil]. Rev. Saúde públ., S. Paulo, 22:118-31, 1988.

ABSTRACT: The objective of this study was to characterize hospital morbidity in the Cubatão County, SP (Brazil), and compare this morbidity rate to that of the State of S. Paulo as a whole in order to identify the principal pathologies and provide information for the county's health services. The characterization of hospital morbidity was based on the analysis of data collected between July/1983 and June/1984. The main causes of admission in the three hospitals in Cubatão County were: complications of pregnancy, childbirth and the puerperium (23.63\%); diseases of the respiratory system (22.8\%); endocrine, nutritional and metabolic diseases and immunity disorders $(10.47 \%)$; diseases of the circulatory system $(10.26 \%)$; injuries and poisoning $(7.63 \%)$; diseases of the genitourinary system $(7.56 \%)$; diseases of the digestive system $(7.16 \%)$. Comparing hospital morbidity in Cubatão that of the State of S. Paulo as a whole a higher frequency rate was observed of diseases of the respiratory system, endocrine, nutritional and metabolic diseases and immunity disorders (basicaly dehydration), and injuries and poisoning. This might be a reflection of the bad environmental and sanitary conditions and poor basic sanitation, the low socioeconomic level of the population and the high industrialization of the county. The low incidence of neoplasms, diseases of the musculoskeletal system and connective tissue anomaties may be related to the precarious health services of the county which encourage the population to seek assistance elsewhere. factors.

UNITERMS: Hospitals, general. Morbidity. Health services research. Socioeconomic 


\section{REFERÊNCIAS BIBLIOGRÁFICAS}

1. ANUÁRIO ESTATÍSTICO DO ESTADO DE SÃO PAULO. (Fundação SEADE). São Paulo, 1980 .

2. FUNDAÇÃO IBGE. Sinopse preliminar do censo demográfico: Sáo Paulo. Rio de Janeiro, 1982.

3. GENTILE DE MELO, C. A epidemiologia da cesárea. In: Gentile de Melo, C. Saúde $e$ assistência médica no Brasil. São Paulo, CEBES-HUCITEC, 1977. p. 121-9.

4. KUNO, R. Estado epidemiológico dos agravos respiratórios na população do Município de Cubatão correlacionados com os niveis de poluição da atmosfera. São Paulo, Companhia de Tecnologia de Saneamento Ambiental, 1984.

5. LEBRÃO, M. L. Morbidade hospitalar no Vale do Paraíba: 1975. São Paulo, 1982. [Tese de Doutoramento - Faculdade de Saúde Pública da USP].

6. MEDRADO-FARIA, M. A. et al. Acidente de trabalho em trabalhadores do setor secundário no Município de Cubatão, São Paulo. Rev. Saúde ocup. Segur., 42:62-84, 1983.

7. PLACECK, J. P. et al. Cesarean section delivery rates: United States, 1981, Amer. J. publ. Hlth, 73:861-2, 1983.

8. RIBEIRO, T. M. Fundamentos e esboço de um projeto para reformular, racionalizar e aperfeiçoar a assistência às crianças e adolescentes portadores de doenças respiratórias. São Paulo, Secretaria de Higiene e Saúde do Município de São Paulo, 1984. [Mimeografado].

9. SALVADOR FILHO, P. et al. Avaliação das emissões de poluentes atmosféricos de origem industrial na região de Cubatão, subsídios para uma política de ação. [Trabalho apresentado no XI Congresso Nacional de Engenharia Sanitária e Ambiental, Fortaleza, 1981].

Recebido para publicação em: 6/4/1987

Reapresentado em: 4/12/1987

Aprovado para publicação em: 8/12/1987 